\title{
Bronconeumonía severa por Staphylococcus aureus: A propósito de un caso
}

\section{Severe bronchopneumonia due to Staphylococcus aureus: A case report}

\author{
Dra.M Anabel Capote Barreras ${ }^{1}$ \\ anabel9512@nauta.cu \\ Roberto Carlos Barletta Farías ${ }^{2}$ \\ Dra.M Liliam Chamizo Marques ${ }^{3}$ \\ liliamchamizo@gmail.com
}

Recibido: 1/07/ 2019; Aceptado: 1/09/2019

\section{RESUMEN}

La bronconeumonía por Staphylococcus aureus es una patología infrecuente y grave, especialmente si se trata de un germen multirresistente. Este microorganismo suele afectar frecuentemente la piel y los tejidos blandos por lo que difícilmente se aísla en otros tejidos. En abril del 2017 se presentó en el Hospital Provincial de Cienfuegos un paciente con una bronconeumonía grave estafilocócica. El presente trabajo tiene como objetivo describir el manejo clínico de la bronconeumonía severa estafilocócica a partir del estudio de un caso. Se concluyó que es una entidad infrecuente, con rápida evolución y mal pronóstico.

Palabras Clave: bronconeumonía, Staphylococcus aureus, multiresistente, infrecuente, grave

\section{ABSTRACT}

Staphylococcic bronchopneumonia is an unusual and severe disease, mainly in its multi-resistant clinical presentation. This microorganism can be easily found on skin and soft tissues but hardly isolated in other tissues. On April of 2017 a male patient was diagnosed with Staphylococcic bronchopneumonia in Cienfuegos main Hospital. This research has as its main objective to describe the management of the disease beginning with the introduction of a particular case. So it has been concluded that this pathology is not frequent, acute and extremely severe.

Keywords: staphylococcic bronchopneumonia, severe, multi-resistant, unfrequent

\footnotetext{
1 Universidad de Ciencias Médicas en Cienfuegos. Cuba

2 Universidad de Ciencias Médicas en Cienfuegos. Cuba

3 Policlínico Hospital Miguel Alipio León. Cuba
} 


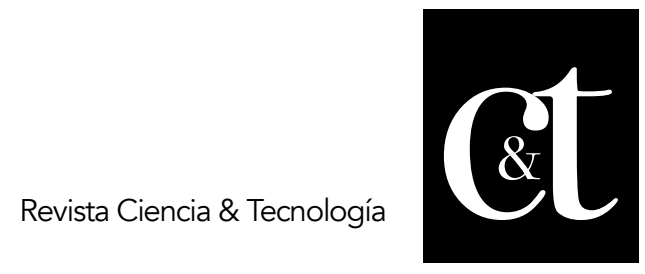

No. 24, 31 de octubre de 2019

ISSN impreso: 1390 - 6321

ISSN online: 2661 - 6734

\section{Introducción}

En los últimos años la humanidad ha vivido un notable incremento de las infecciones por gérmenes multirresistentes, a tal punto que la Organización Mundial de la Salud ha designado dicha problemática como uno de los tres grandes retos que enfrenta la salud mundial.

Los miembros del género Staphylococcus son cocos grampositivos de 0,5 a $1 \mu \mathrm{m}$ de diámetro, dispuestos en racimos, inmóviles, no esporulados, catalasa positiva y generalmente producen una microcápsula de naturaleza polisacárida. Se reconocen actualmente 35 especies y 17 subespecies diferentes, muchas de ellas forman parte de la flora microbiana de la piel en humanos y otras de la flora de otros mamíferos y aves. Staphylococcus aureus, el patógeno humano más importante del género, produce infecciones de piel y tejidos blandos, infecciones invasoras y cuadros tóxicos. El resto de especies, conocidas como estafilococos coagulasa negativos, actúan sobre todo como patógenos oportunistas en pacientes hospitalizados.

El Staphylococcus aureus fue descrito por primera vez en el año 1880, concretamente en la ciudad escocesa de Aberdeen, por el cirujano Alexander Ogston en el pus que drenaba un absceso infectado. Su nombre deriva del griego staphylé ("en racimo de uvas"), debido a la morfología que adoptan las células de Staphylococcus en las tinciones que se realizan a partir de cultivos en medios de agar.

En 1941, las infecciones estafilocócicas eran erradicadas por penicilina. Un poco más tarde, en 1945, Sprink Ferris reportó una cepa de $S$. aureus resistente a la penicilina que, por la acción de una $\beta$-lactamasa, la destruía. A fines de los años 80 , emergieron en Australia los primeros aislamientos de $S$. aureus resistentes a meticilina en la comunidad, con un perfil de susceptibilidad distinto al observado en cepas de origen nosocomial. Una situación similar vivió Japón en 2003 y en EE. UU. a fines de los 90, definiéndose como Staphylococcus aureus resistente a meticilina adquirido en la comunidad (SARM-AC). S. aureus es un patógeno oportunista que forma parte de la microflora humana, pudiendo estar colonizada por esta bacteria entre el $30 \%$ y el $50 \%$ de la población, siendo la localización más frecuente la colonización nasal. El principal reservorio de $S$. aureus lo constituye el hombre enfermo o portador. La frecuencia de colonización es más frecuente en el medio hospitalario, especialmente en pacientes sometidos a hemodiálisis, diabéticos tipo I, pacientes con lesiones cutáneas, sujetos infectados por el VIH y en adictos a drogas por vía parenteral (ADVP).

La infección por $S$. aureus se produce tras lesiones cutáneas, traumáticas o quirúrgicas que favorecen la penetración del microorganismo desde la piel hasta los tejidos profundos. Estos procesos infecciosos varían desde el Síndrome del Shock Tóxico, el Síndrome de la Piel Escaldada estafilocóccica, abscesos cutáneos, celulitis, foliculitis hasta cuadros graves de neumonía, meningitis, endocarditis, pericarditis, entre otras. La neumonía estafilocócica es un cuadro infrecuente pero grave, se puede producir por aspiración de secreciones orales o por diseminación hematógena. Esta última se produce generalmente a partir de una endocarditis derecha, de una tromboflebitis séptica o de una infección de cable de marcapasos. La neumonía por aspiración de adquisición comunitaria se produce como complicación de cuadros víricos, mientras que la nosocomial es más frecuente en pacientes sometidos a ventilación mecánica. La complicación más frecuente de la neumonía es el empiema (Borraz, 2017, IDSA, 2011). 


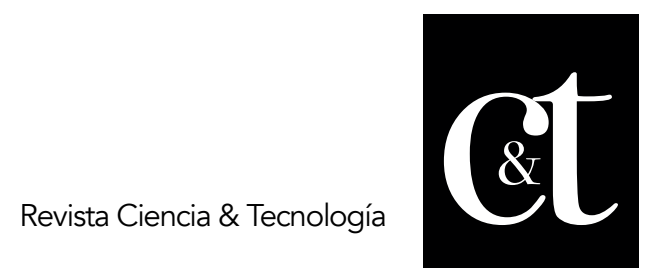

No. 24, 31 de octubre de 2019

ISSN impreso: 1390 - 6321

ISSN online: 2661 - 6734

En la actualidad la existencia de cepas de SARM sigue siendo un reto para la terapéutica. Se han descrito varios mecanismos que le confieren resistencias a dichas cepas de Staphylococcus aureus: la resistencia mediada por $\beta$ - lactamasas, el fenómeno de tolerancia, la modificación del sitio de acción, la presencia de bombas eflujo y la presencia del gen mecA. (Borraz, 2017, Martins, 2014, Predari, 2013).

En España los últimos trabajos del Grupo de Estudio de Estafilococos reflejan un aumento de SARM de probable origen comunitario que varía desde el $5 \%$ en el año 1986 al $17,8 \%$ en el 2002; la mayoría de los datos disponibles proceden de estudios hospitalarios, que informan tasas muy variables sobre los casos de SARM. (Borraz, 2017).

Los brotes causados por SARM asociado a la comunidad no sólo afectan a poblaciones relativamente cerradas, como cárceles, cuarteles, guarderías, sino que también es causante de brotes en equipos de atletas, sobre todo en deportes donde se produce un contacto directo de piel entre los deportistas. También se han publicado datos que afirman un aumento de la colonización por SARM entre miembros de "poblaciones cerradas" como son las comunidades de los aborígenes de Australia y los indios de América. Esta alta tasa de SARM-AC puede estar asociada con factores de riesgo difundidos en la comunidad como son el aumento de las infecciones de piel, el hacinamiento y el uso de antibióticos de amplio espectro (Borraz, 2017).

Las cifras de prevalencia se comportan de manera muy variable cuando se comparan de un país a otro: en los países asiáticos (Corea del Sur, Vietnam o Taiwán), superan el $60 \%$; en el norte de Europa (Noruega, Suecia, Dinamarca y Holanda) son muy bajas (< $1 \%)$; y en España superan el 43,1\% (SARM, 2017).

En Cuba, particularmente en centros hospitalarios de la capital, se ha reportado en los últimos años una incidencia creciente de afecciones producidas por este microorganismo, con cifras que varían entre un 60 y 70 \% (González, 2013).

Acerca del comportamiento de la infección por SARM en Cienfuegos, en un estudio realizado en el Hospital Dr. Gustavo Aldereguía Lima en el año 2010 utilizando el método Oxacillin Salt-Agar Screening-Platese se detectó SARM en el 14\% de los aislamientos, mientras que en un estudio realizado en la misma institución de salud en el año 2014 de un total de 142 muestras analizadas, se aisló SARM en un $55.0 \%$ de ellas, lo que confirma un aumento de la incidencia de dicho microorganismo no solo a nivel mundial sino también en nuestro país y en nuestra provincia (MartínezOquendo, 2017).

Objetivo

Describir el manejo clínico de la bronconeumonía severa estafilocócica a partir de un caso.

\section{Desarrollo}

Presentación del caso 


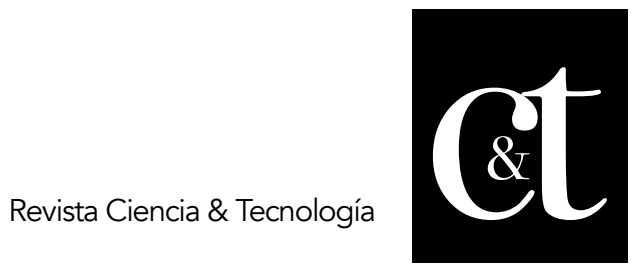

No. 24, 31 de octubre de 2019

ISSN impreso: 1390 - 6321

ISSN online: 2661 - 6734

Paciente de 39 años de edad, blanco, masculino, de procedencia rural, con Antecedentes Patológicos Personales de Hipertensión Arterial con tratamiento regular con Atenolol 1/2 tableta cada 12 horas e Hidroclorotiazida 1 tableta al día; además padece de Gota con tratamiento regular con Colchichina, sin precisar tiempo de evolución de dichas enfermedades.

Acude al hospital refiriendo como problema principal imposibilidad para movilizar los miembros inferiores. Refiere que todo comenzó tres días antes, luego de haber realizado un esfuerzo físico, en este caso, levantar un gran peso sobre la espalda, luego de lo cual comenzó a presentar dolor lumbar que fue incrementando de intensidad gradualmente hasta que la noche antes de acudir al hospital presentó, además, dolor punzante que tomaba hasta los dedos de los pies e imposibilidad para mover ambos miembros inferiores; refirió también falta de aire.

Al examen físico del ingreso presentaba como datos positivos: una polipnea superficial con una frecuencia respiratoria de 28 respiraciones por minuto; dolor a la palpación en la musculatura dorsal, además, paraplejía de miembros inferiores, arreflexia cutáneo-plantar, aquileana y rotuliana, hipoestesia hasta la región de L3 y toma del esfínter vesical. Se encontraba consciente, orientado, normotenso, normocárdico y afebril.

Se realiza en Cuerpo de Guardia del Hospital Provincial un Rayos-X simple de columna lumbar de vista anteroposterior y lateral en el cual no se constata alteraciones. Teniendo en cuenta todo lo anterior se decide su ingreso en el servicio de Neurocirugía con una Impresión Diagnóstica de Traumatismo raquimedular y se impone tratamiento en sala con Metilprednisolona y Manitol al $20 \%$ teniendo en cuenta dicho diagnóstico.

Durante su primer día de evolución en sala, a las pocas horas de haber ingresado, comienza a presentar movimientos involuntarios del brazo derecho, tendencia a la somnolencia, hipertensión $(140 / 90 \mathrm{mmHg})$, distensión abdominal, fiebre de $38,5^{\circ} \mathrm{C}$ y tiene una convulsión, la cual se trata con Fenitoína. Luego de precisar dichos hallazgos se traslada para realizar una tomografía axial computarizada (TAC) de la columna dorsolumbar buscando lesiones óseas medulares, sin embargo en la TAC solo se detectan lesiones pulmonares de aspecto inflamatorio y derrame pleural bilateral, que no pueden ser bien precisadas pues inicialmente el objetivo de la TAC no era obtener imágenes pulmonares. Al ser trasladado nuevamente a la sala se constata que había evolucionado rápidamente a un estado con deterioro de la conciencia y distrés respiratorio por lo que se hacía evidente la necesidad de ventilación mecánica y por lo tanto traslado a Unidad de Cuidados Intensivos (UCI) ahora con un diagnóstico de shock medular.

Se recibe en la UCI Polivalente alrededor de las 19 horas con fiebre, hipotenso, hiperventilando y con ruidos hidroaéreos ausentes, por lo que se decide entubar y acoplar a ventilador mecánico, sedar con Midazolam, administrar drogas vasoactivas (Norepinefrina), iniciar tratamiento con antimicrobianos (Cefotaxima) y aplicar medidas descompresivas. Se habían realizado complementarios donde se observaba leucocitosis (más de $20 \times 10^{9} \mathrm{~mm}^{3}$ ) a predominio de segmentados (90\%), Hemoglobina $102 \mathrm{~g} / \mathrm{L}$ y un Ultrasonido Abdominal que informaba hígado graso, litiasis en vías biliares, estómago dilatado con contenido líquido y derrame pleural bilateral de pequeña cuantía en pleura derecha y de mediana cuantía en la izquierda. 


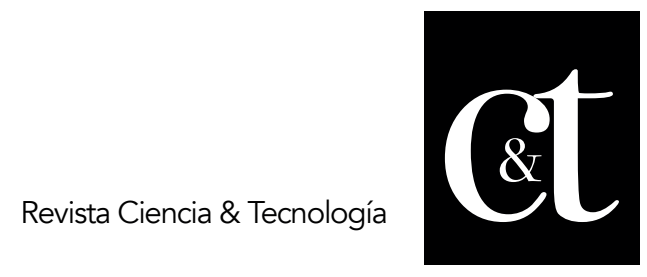

No. 24, 31 de octubre de 2019

ISSN impreso: 1390 - 6321

ISSN online: 2661 - 6734

A las 23 horas del mismo día se le realiza una toma de Rayos $X$ simple de tórax de vista anteroposterior, en el cual se encuentran lesiones de aspecto inflamatorio en ambos campos pulmonares, con aspecto de moteado difuso, compatibles con bronconeumonía de posible etiología bacteriana; por lo anterior se decide disminuir dosis de Metilprednisolona. Además estaba presentando fiebre mantenida que iba en ascenso e hipotensión marcada a pesar de uso de drogas vasoactivas por lo que indican otras dos drogas (triple apoyo vasoactivo con Dopamina y Dobutamina) y cambiar antibioterapia pon Meropenem y Metronidazol. A las 23:55 horas se le realiza punción lumbar para estudio del líquido cefalorraquídeo (LCR).

A las 4 am del día siguiente la diuresis se hace escasa y se constatan cifras elevadas de creatinina $(323 \mathrm{mmol} / \mathrm{l}$ ) por lo que se plantea una probable insuficiencia renal aguda prerrenal en el curso de shock séptico. Además se constata la aparición de lesiones en la piel redondeadas a predominio en tronco y miembros inferiores de color rojo y bordes eritematosos por lo que se plantea una posible reacción medicamentosa o la presencia de una enfermedad por Staphilococcus aureus.

A las 9 am las lesiones en piel antes descritas se hicieron más evidentes, con centro blanco amarillento y se encontraban más diseminadas. No presentaba fiebre y la diuresis continuaba escasa. Se decide agregar a la terapia antimicrobiana Vancomicina a dosis renal.

A las 13 horas luego de haber vuelto a entrevistar a los familiares en búsqueda de datos adicionales que puedan ayudar con el caso, pues los nuevos hallazgos no parecían corresponderse con el diagnóstico inicial, se recoge el dato de que el paciente presentaba un forúnculo en la parte superior de la espalda, que se encontraba enrojecido y con punto amarillo en el centro. Para estos momentos el paciente presentaba fiebre mantenida de $40^{\circ} \mathrm{C}$, hipotensión severa y taquicardia.

Se recibe informe de LCR en el cual se constata: color amarillo- transparente, pandy positivo, con predominio linfocitario.

A las 16 horas se recibe resultado de hemogasometria arterial la cual constató: $\mathrm{pH}-$ 7.23; PCO2- $53.6 \mathrm{mmHg}$; PO2- $64 \mathrm{mmHg}$; HCO3- $21.9 \mathrm{mmol} / \mathrm{l}$. Se precisa Acidosis Respiratoria y se procede a corregirla con ajuste ventilatorio.

Durante las horas siguientes continuó presentando fiebre que nunca estuvo por debajo de los $40^{\circ} \mathrm{C}$, taquicardia y estados en los que alternaba la hipotensión e hipertensión.

Así se comportó todo hasta que alrededor de las 9 am del día siguiente (tercer día desde el ingreso) entró en parada cardiorrespiratoria en ritmo de asistolia. Fue reanimado durante aproximadamente 30 minutos y se administran durante la parada epinefrina y bicarbonato de sodio sin respuesta. Se declara fallecido, donde se señala la causa directa de la muerte como Shock séptico secundario a Bronconeumonía Bacteriana Grave a germen no precisado.

Se realiza necropsia la cual arrojó las siguientes conclusiones:

Causa directa de muerte (CDM): Bronconeumonía bacteriana bilateral severa con pleuritis aguda fibrinosa asociada. Se aisló Staphylococcus aureus. 


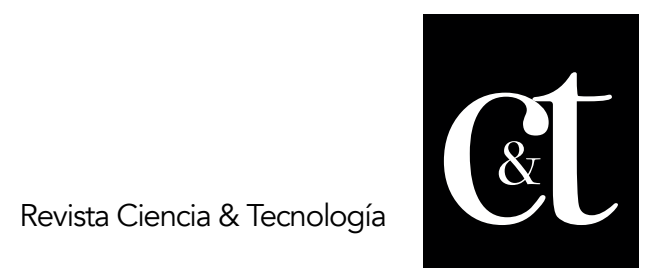

No. 24, 31 de octubre de 2019

ISSN impreso: 1390 - 6321

ISSN online: 2661 - 6734

Otros diagnósticos: hipertrofia del ventrículo izquierdo, coronarioesclerosis leve, cardioangioesclerosis moderada, daño ateroesclerótico en válvula mitral, ateromatosis severa de aorta y sus ramas, nefroangioesclerosis arterial y arteriolar, gastritis y duodenitis crónica moderada, quistes renales corticales bilaterales, pielonefritis crónica bilateral, esplenitis aguda reactiva, hialinosis esplénica, congestión aguda hepática, esteatosis hepática moderada, hígado de éstasis pasivo crónico, congestión visceral generalizada y antracosis.

\section{Resultados}

Se trata de un caso atípico pues las manifestaciones de este paciente al ingreso y el antecedente de haber levantado una carga pesada sobre la espalda no permitieron que el diagnóstico fuera inicialmente acertado.

El diagnóstico de trauma medular parecía corresponderse con las manifestaciones presentadas al inicio del cuadro; sin embargo la respuesta al tratamiento no fue adecuada a pesar de haber sido el correcto (tratamiento con esteroides) para dicho diagnóstico.

Mientras tanto el paciente evolucionaba rápidamente hacia la gravedad y el estado de shock, presentando cada vez más signos de mal pronóstico y una respuesta poco consecuente al tratamiento impuesto a medida que iba avanzando el tiempo, algo no esperado tratándose de un paciente joven. Además de la aparición paulatina de nuevos hallazgos (fiebre alta mantenida que no cedía a pesar de medidas antitérmicas y antipiréticos, lesiones en la piel difusas eritematosas luego de la administración de antimicrobianos) que cada vez se alejaban más del diagnóstico planteado al inicio.

Uno de los hallazgos clínicos más importantes durante el ingreso de este paciente fue la presencia del forúnculo en la región superior de la espalda, que hubiese hecho sospechar de una sepsis por Staphylococcus aureus más tempranamente, pero fue encontrado tardíamente y luego de haberse manejado varios posibles diagnósticos con este paciente, no obstante la evolución de este paciente fue hacia la gravedad y la muerte fue rápida e imprevista, lo que hace pensar que en este caso se trataba de un germen multirresistente ya que independientemente de la sospecha diagnóstica con la que se estaba trabajando fue tratado con antibióticos que en su espectro comprenden al Staphylococcus aureus, díganse Meropenem y Vancomicina.

Se le realizaron durante el ingreso además múltiples exámenes complementarios incluidos química sanguínea (hemograma, leucograma, creatinina, glicemia y otros), estudios imagenológicos (ultrasonido, TAC y rayos $\mathrm{X}$ ), estudios del líquido cefalorraquídeo (a partir de punción lumbar) y microbiológicos (hemocultivo cuyo resultado no fue recibido sino hasta después del fallecimiento), sin embargo, el diagnóstico definitivo de este paciente solo pudo ser realizado durante la necropsia, donde fue finalmente aislado el germen causante de esta grave patología: Bronconeumonía bacteriana bilateral severa por Staphylococcus aureus.

\section{Conclusiones}

La bronconeumonía estafilocócica es una patología muy grave, infrecuente y de rápida evolución. 


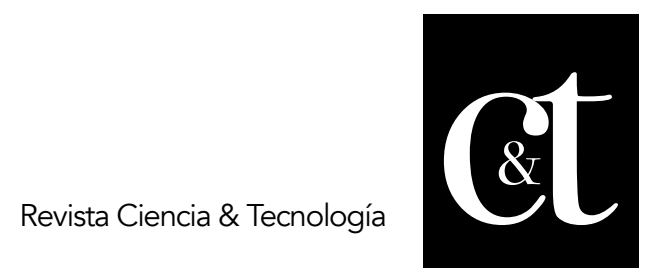

No. 24, 31 de octubre de 2019

ISSN impreso: 1390 - 6321

ISSN online: 2661 - 6734

El diagnóstico de esta enfermedad requiere tener en cuenta componentes clínicos, imagenológicos y microbiológicos.

El tratamiento oportuno es la clave para mejorar el pronóstico de los pacientes que sufren de bronconeumonía severa por Staphylococcus aureus.

\section{Referencias bibliográficas}

Borraz Ordás. C. (2006). Epidemiología de la resistencia a meticilina en cepas de Staphylococcus aureus aisladas en Hospitales españoles. Tesis Doctoral. Universidad de Barcelona, España; Disponible en: www.tdx.cat/handle/10803/2513

Garza-Velasco, R., Zúñiga-Rangel, O., Perea-Mejía, LM. (2013). La importancia clínica actual de Staphylococcus aureus en el ambiente intrahospitalario. Educ. quím. Vol. 24 (1). Descargado de: http://www.scielo.org.mx/scielo.php?script =sci_arttext\&pid $=$ S0187- 893X2013000100002.

González, M. (2013). Resistencia antimicrobiana, una amenaza mundial. Revista Cubana de Pediatría. Vol. 85(4): Descargado de: http://bvs.sld.cu/revistas/ped/vol85_4_13/ped01413.htm.

Infectious Diseases Society of America. IDSA. (2011). Announces First Guidelines for Treatment of Methicillin Resistant Staphylococcus aureus (MRSA) Infections [Internet]. Arlington: Recuperado de: http://www.idsociety.org/IDSA_Guidelines_for_Treatment_of_MRSA_Infections /.

Martins, A., Riboli, D., Pereira, V., Ribeiro, M. (2014). Molecular characterization of methicillin-resistant Staphylococcus aureus isolated from a Brazilian university hospital. Braz J Infect Dis. V. 18(3):pp. 331-5. Recuperado de: https://www.ncbi.nlm.nih.gov/pubmed/24389283

Martínez-Oquendo, A., Montes-de-Oca-Rivero, M., Alemañy-Co, J., Marrero- Silva, I., Reyna-Reyes, R., Cedeño-Morales, R. (2017) Resistencia antimicrobiana del Staphylococcus aureus resistente a meticilina en el Hospital Dr. Gustavo Aldereguía Lima. Medisur. V. 15(2): pp. 210-216. Descargado de: http://www.medisur.sld.cu/index.php/medisur/article/view/3321

Predari SC. (2013) La nickingenzyme de Staphylococcus aureus, un blanco de acción muy promisorio. Medicina. 73 (4), pp. 376-378. Recuperado de: http://www.medicinabuenosaires.com/revistas/vol73-13/4/376-378-MED46069EDIT_predariA.pdf-.

Rodríguez RD, Bustillo DE, Caicedo DC, Cadena DC, Castellanos C. (2016). Acinetobacter baumannii: patógeno multirresistente emergente. MÉD.UIS. 2016; 29(2):113-35.

Rodríguez Tamayon, E., Jiménez Quiceno, J. (2015) .Factores relacionados con la colonización por Staphylococcus aureus. Iatreia. Vol. 28 (1), pp. 66-77.

Sánchez Lerma, L., Pavas Escobar, N., Rojas Gulloso, A., Pérez Gutiérrez, N. (2016). Infecciones por Staphylococcus aureus resistente a la meticilina adquirido en la comunidad en pacientes de Villavicencio, Colombia. Rev Cubana Med Trop. V. 68(1), pp. 159-162. Recuperado de: http://scielo.sld.cu/scielo.php?script=sci_arttext\&pid=S037507602016000100004.

Toribio MS, Fernández JG. (2017). Staphylococcus aureus resistente a meticilina: una emergencia sanitaria en medicina humana y una alerta para la ciencia veterinaria. Revista Ciencias Veterinarias. Vol. 15(1); pp. 83-96. Recuperado de: www.biblioteca.unlpam.edu.ar/pubpdf/revet/v15n1a07toribio.pdf.

Van, J., Mowery, J., Piraino, M., Nava, R., Kohn, C. \& Hoet, A. (2014). Molecular 


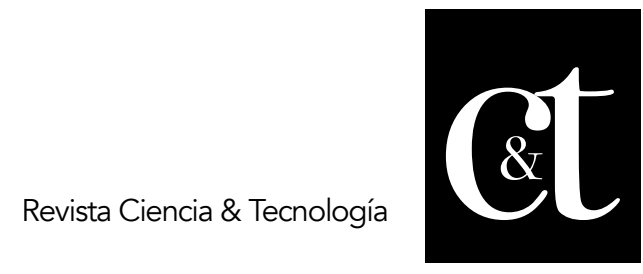

No. 24, 31 de octubre de 2019

ISSN impreso: 1390 - 6321

ISSN online: 2661 - 6734

epidemiology of environmental MRSA at an equine teaching hospital: introduction, circulation and maintenance. Vet Res. Veterinary Research V. 45(1):31. Recuperado de: https://www.ncbi.nlm.nih.gov/pubmed/24641543. 